\title{
Cuerpo, control y resistencia. Discursos de la inseguridad y prácticas del miedo en un distrito de Madrid
}

\author{
Body, Control and Resistance: \\ Lack-of-Safety and Fear-Related Practices in a District \\ of Madrid
}

\author{
Sergio García García \\ Departamento de Antropología Social. \\ Facultad de CC. Políticas y Sociología \\ Universidad Complutense de Madrid
}

\section{RESUMEN}

A partir de los avances en la investigación etnográfica sobre los discursos de la (in)seguridad y las prácticas relacionadas con el miedo en un distrito de Madrid (Carabanchel), el autor trata de repensar la corporalidad como el ámbito excluido por los discursos procedentes de los lugares de poder. El discurso de la inseguridad ciudadana, que ha ido ganando espacio en ciertos ámbitos expertos, simula representar a las subjetividades inseguras contemporáneas, pero en su intento no hace sino producir sujetos representables. Se oculta la historia que habita en los cuerpos, incluida la de los miedos vividos, y se devuelve un discurso, el de la inseguridad, que se erige en solución de protección. Pese a que estos discursos se incorporan y se actúan performativamente por parte de los habitantes de un barrio señalado como peligroso, se producen resignificaciones en el ámbito de la oralidad, capaces de atenuar el impacto de las estrategias de control.

Palabras clave: Inseguridad, Miedo, Carabanchel, Discurso, Oralidad, Espacio público.

\section{SUMMARY}

The author draws on his fieldwork findings concerning discourses on safety —or lack thereof- and fear-related practices in Carabanchel, a district of Madrid, to reflect on the body as the realm that discourses coming from the places of power ignore. Increasingly popular among experts, the discourse on the citizens' lack of safety pretends to represent contemporary subjective insecurities while actually producing subjects in the process that can be represented. It hides the story living in the bodies, including the story of experienced fears, and returns a narrative - that of lack of safety- portrayed as a 
solution for protection. Notwithstanding that these discourses are incorporated and acted out by the inhabitants of a neighbourhood considered dangerous, the observer can obtain oral re-significations with which to mitigate the effect of control strategies.

Key words: Unsafety, Fear, Carabanchel, Discourse, Orality, Public Space.

\section{INTRODUCCIÓN}

El cuerpo es un espacio sobre el cual se establecen las marcas de la dominación, pero es al mismo tiempo la materia que actúa las resistencias. Las relaciones de poder no se marcan desde una exterioridad corporal, sino a partir de la apropiación de la dominación por parte del dominado (Butler 2007a). A partir del desarrollo de una investigación etnográfica relativa a los discursos de la inseguridad y las prácticas relacionadas con el miedo en un distrito de Madrid, Carabanchel, voy a tratar de explicitar algunas reflexiones inconclusas en relación a la corporalidad como espacio en el que se juegan y se actúan las relaciones de poder en las que se ven inmersos los habitantes del distrito.

El cuerpo actúa el miedo a partir de su relación más o menos violenta con otros cuerpos y con los discursos. Esta violencia en la interacción no debe entenderse únicamente como agresión física, sino como relación de dominación. Pero la dominación no es mera obligación externa, sino asunción de la misma por parte de quien la sufre. Foucault teorizó sobre las "tecnologías del yo", aquellas que permiten a los individuos realizar una serie de operaciones sobre sus cuerpos y sus conductas con el fin de gobernarse y alcanzar determinados fines (citado en Amuchástegui 2007). Por esta razón, el "cuidado de sî", al mismo tiempo que asunción de la dominación, vendría a remitir a las técnicas de subjetivación, aquellas que aluden a los campos de libertad en los que se pueden construir relaciones innovadoras, no reguladas. Estas nuevas relaciones constituyen las manifestación de la performatividad de acciones pasadas: los efectos de estas acciones no son consecuencia de una intencionalidad subjetiva (ni siquiera de quienes ejercen más poder), sino de una recombinación más o menos azarosa de significados. Los procesos de subjetivación carecen de centro, no son identitarios y pertenecen a la micropolítica, por lo que, desde esta perspectiva, resulta más adecuado hablar de agencias que de sujetos $^{1}$. Podemos comenzar a

\footnotetext{
${ }^{1}$ Empleo "agencialidad" para referirme a la autoría sin intencionalidad de una acción, tal y como lo han hecho previamente destacados sociólogos como Bourdieu y Giddens y teóricas feministas como Judith Butler. El concepto de "agencialidad" vendría a discutir el de "sujeto" por las asociaciones al actor racional de la modernidad que se le han imputado a éste último.
} 
rastrear huellas de subjetivación incluso en los entornos más totalitarios, aquellos en los que se espera una unidireccionalidad absoluta en el ejercicio del poder. Ésta es la tarea que me propongo en el presente artículo: mostrar cómo la agencialidad persiste a pesar del control (discursos de la inseguridad) y el miedo (que habita en la corp-oralidad²).

Desde la perspectiva foucaultiana, todo ejercicio del poder engendra resistencia. Judith Butler, analizando el sistema de sexo-género, afirma que la Ley constituye su propia oposición y su subversión: "lo impensable está completamente presente en la cultura, pero completamente excluido de la cultura dominante" (Butler 2007b: 170). Recogiendo estas premisas, en mi investigación considero que el discurso de la inseguridad pertenece al campo de la identidad y de lo macropolítico, mientras que el miedo habita en la corp-oralidad y lo micropolítico. Podemos comenzar a pensar, entonces, que en las prácticas de subjetivación de la inseguridad hay márgenes para la libertad y la creatividad. Si bien esto no implica que dichas prácticas conduzcan a acciones colectivas de resistencia, parece razonable pensar que los márgenes no regulados están abiertos históricamente a los efectos no intencionales de toda acción y de todo discurso, y que por tanto, en algún momento el discurso de la "inseguridad ciudadana" puede tornarse en movilización colectiva contra quienes lo promueven.

Parto, entonces, de que la inseguridad y el miedo pueden derivar en acciones inesperadas. Prueba de la variedad de usos posibles del miedo fue una situación de tensión observada en una manifestación contra el derribo de la cárcel de Carabanchel entre unos vecinos y un guardia de seguridad con un perro (ambos en una posición agresiva): dos niños de la misma edad que estaban con un pariente adulto reaccionaron de distinta manera. Pude percibir que a ambos les generó tensión la situación, y podemos llamar miedo a lo que produce esa tensión emocional. Sin embargo el miedo parece no ser determinante: cada cual actuó su miedo de formas diferentes, uno queriendo introducirse en el conflicto, ver qué pasaba o incluso coger piedras, y el otro pidiendo al adulto irse mientras se situaba cuerpo con cuerpo a su lado y le pasaba la mano por la espalda, diciendo en un tono quejoso "no quiero que me peguen". Con este ejemplo trato de ilustrar cómo el miedo corporal no determina las acciones (frente a su concepción como herramienta política paralizadora). Voy a realizar un recorrido "liberador" que

${ }^{2}$ Escribo "corp-oralidad" interrumpiendo la continuidad entre los dos conceptos que contiene el término con un guión con el fin de dar cuenta de la diferencia entre las prácticas actuadas con el cuerpo y aquellas que se efectúan mediante el habla, pero tratando de evocar, al mismo tiempo, su profunda imbricación como orden diferenciado (el de las prácticas) con respecto al discurso. 
va desde las tecnologías de sujeción a las respuestas más innovadoras de los agentes del barrio. Para ello me serviré del marco teórico de Michel de Certeau y de otros autores que han distinguido los discursos y las identidades de la oralidad y la corporalidad. Intentaré mostrar cómo las políticas de control y las rémoras de la sociedad disciplinaria son incapaces de anular la agencialidad de los habitantes del barrio, que a través de su corporalidad pueden plantear respuestas creativas y autogestionarias ( $\sin$ recurrir a la autoridad) del miedo.

\section{SOCIEDADES DE CONTROL Y DE CONSUMO}

Si el disciplinamiento se constituía en el objeto de las tecnologías de poder en las primeras etapas del capitalismo industrial (siendo el fordismo su apoteosis), en las sociedades occidentales han ido ganando peso otros regímenes de subjetividad. Éstos consisten en el control preventivo por parte de las autoridades de los cuerpos no consumidores (no ciudadanos) y no disciplinables (excedentes humanos), por un lado, y en el autocontrol por medio del consumo entre aquellos que disponen de cierto poder adquisitivo y ciudadanía, por otro. Algunos autores vienen describiendo el tránsito desde las sociedades disciplinarias a las sociedades de control (Hardt y Negri 2005; de Giorgi 2006). Estas sociedades surgidas al compás del neoliberalismo necesitan ejercer un control preventivo sobre los cuerpos previamente excluidos. Zygmunt Bauman, tratando de acercarse a la construcción de subjetividades y corporalidades en estas sociedades móviles y de control, cita la descripción de los espacios de exclusión llevada a cabo por Flutsy: el "espacio espinoso" que evita que nadie se siente, el "espacio resbaladizo" al que no se puede acceder, el "espacio aprensivo" vigilado por cuerpos humanos o máquinas de seguridad, etc. (citado en Bauman 2006: 30-31). Por otro lado, el propio Bauman establece un puente entre el control contemporáneo y el consumismo. Tanto en una lógica social como en la otra, podemos apreciar la dificultad del encuentro entre heterogéneos. Bauman ve en la nueva arquitectura urbana o en la estructura del centro comercial que coloniza el tiempo de ocio la combinación de ambos procesos formativos. En ambas figuras arquitectónicas se establece una segregación de los cuerpos, fruto del control preventivo ejercido sobre los no consumidores y del autocontrol llevado a cabo por los consumidores ${ }^{3}$.

${ }^{3}$ A propósito de este razonamiento de Bauman, una serie de observaciones efectuadas en la zona más moderna de Carabanchel me han abierto una línea de investigación centrada en la separación entre los cuerpos en los nuevos espacios. Una nueva megasuperficie comercial en los límites de Carabanchel (que son los de la ciudad), si- 
Para Bauman, la modernidad fue haciendo cada vez más legible el espacio de cara a su instrumentalización por parte del poder. Los mapas son un claro ejemplo de ello: de su intento de ser un reflejo del espacio pasaron a guiar la representación del mismo y a orientar a sus practicantes. El urbanismo de Le Corbusier constituye un punto álgido en el intento de los poderes de aniquilar la espontaneidad en el espacio urbano (Bauman 2006: 49-62). La oportunidad para el ejercicio colectivo de la responsabilidad queda desechada por el intento de los poderes de infantilización generalizada (que como en Madrid, prohiben, vigilan y limitan espacios festivos populares y organizan simultáneamente grandes eventos espectaculares, como la "Noche en Blanco"). Si a la mercantilización y la abolición de la espontaneidad en la ciudad le añadimos el retroceso del Estado Social, las intervenciones estatales que más peso ganan son las que brindan seguridad al servicio de los intereses corporativos y de la diferenciación clasista ${ }^{4}$.

En estas condiciones, se produce una estratificación en función de la capacidad de movimiento. El empresario, conferenciante, congresista, turista, etc., contrasta con el migrante "sin papeles" o el "vagabundo" (Bauman 2006: 128). Del mismo modo, el privilegiado que se encierra voluntariamente en su gated comunity contrasta con el nuevo pobre encerrado contra su voluntad como solución a su exclusión. El enemigo interno, el migrante, es el nuevo y potente contraste negativo en las sociedades de control y de con-

tuada precisamente en un barrio de reciente construcción (PAU de Carabanchel) de viviendas de manzana cerrada y trazado de calles pensado para la movilidad en coche, trata de individualizar, de estetizar y de erotizar las experiencias de los cuerpos que lo visitan. Al mismo tiempo, el centro comercial está dispuesto para la separación de cuerpos mediante la individualización de los deseos, la generación y mercantilización de las frustraciones (de cuerpos que se sienten insuficientes) y la mediatización de los contactos (el tacto desaparece, no hacen falta manos que abran puertas y grifos, ya las detecta un sensor electrónico). Se trata de un espacio que promueve una sensación de amplitud, de horizonte, de libertad, de mundo autocompleto con clima cálido en el que no se ve lo otro (presente en colonias de viviendas para personas empobrecidas muy cercanas al centro comercial o en el cementerio aledaño), lo que molesta, lo que recuerda que el mundo es heterogéneo e injusto y que puede frenar el impulso de consumir al generar cuestionamiento. El centro comercial es, quizás, el paradigma del espacio antihistórico y sucedáneo de una sociedad de consumo y de control: trata de producir una ilusión de completud y de seguridad personal. Su protección es identitaria, pero nunca corporal.

${ }^{4}$ La reflexión sobre la inseguridad y el miedo urbano en el campo de la antropología y la sociología ha encontrado la génesis de la actualización del problema en el retroceso del Estado Social y de los valores igualitarios en las sociedades contemporáneas y en el avance del discurso mediático de la inseguridad como correlato del auge cultural del neoliberalismo. Algunas de las reflexiones más destacadas las encontramos en Reguillo (2002, 2005), Wacquant (2001), Caldeira (2000) o Low (2004). 
sumo europeas y norteamericanas. La movilidad de unos se produce gracias a la inmovilidad de otros. Más que a una sociedad disciplinaria y panóptica nos acercamos a otra de prevención y separación de cuerpos.

RELACIONES SECURITARIAS EN CARABANCHEL: DE LA ARQUITECTURA A LOS CUERPOS

La proliferación de espacios penales y el endurecimiento de las leyes para llenarlos nos hablan de nuevas corrientes en la gestión de la alteridad y la exclusión (Bauman 2006: 135-166). Este tránsito hacia las nuevas formas de gestión no conlleva la desaparición completa de las anteriores. Así, en el entorno urbano en el que investigo, el ya antiguo disciplinamiento convive con el autocontrol (ciudadanos) y el control preventivo de cuerpos (no ciudadanos). A continuación voy a detenerme en la relación intercorporal que se produce en las relaciones securitarias.

Carabanchel es un barrio penal famoso por su vieja cárcel y su perfecto panóptico. El estigma de ese edificio era capaz de derribar simbólicamente sus muros y de establecer un continuo entre el barrio y la delincuencia. Aún hoy, para muchas personas ajenas al barrio, Carabanchel significa cárcel. El objetivo de esta institución, símbolo del franquismo y con la cúpula más grande de Madrid, era controlar cuerpos dentro y fuera de la misma ${ }^{5}$, pero las nuevas tendencias penitenciarias en las sociedades postindustriales persiguen una mayor invisibilización y estetización de las prácticas penales ${ }^{6}$. Por eso son menos conocidos otros dispositivos de encierro del barrio, como los centros de reforma para menores o el Centro de Internamiento de Extranjeros (CIE). Uno de los responsables de la seguridad privada en uno de los centros de menores del distrito refería que "no es que me haya portado mal con los chavales, pero en alguna intervención fuerte se han hecho daño". La fórmula eufemística "se han hecho daño", que quiere significar que la lesión es una suerte de autolesión, está indicando la necesidad de mantener un discurso de corrección social, dada la supuesta protección de los menores en una sociedad que trata de desresponsabilizarlos políticamente al máximo (y sin embargo, cada vez más, carga sobre ellos responsabilida-

\footnotetext{
5 Parte de este análisis se lo debo a Carmen Ortiz (en comunicación personal, 2008).

${ }^{6}$ Mike Davis ya detectaba una estrategia iniciada por las autoridades de Los Angeles en la década de 1980 que hacía compatible los intereses comerciales de la ciudad (salvaguardando la imagen) y el aumento de las instituciones carcelarias (ante la creciente criminalización de diversos colectivos). El cambio de imagen de la arquitectura de prisiones (estetizada con diseños de arquitectos de prestigio que incorporaban elementos propios de otro tipo de edificios, como salas de recepción de estilo hotelero, colores pastel...) permitía aplacar las actitudes "no in my back-yard" y reorientar la visión sobre estos edificios (Bastillas postmodernas) (Davis 1992: 253-257).
} 
des penales). Otro policía del distrito, éste de un cuerpo público, a veces tenía que "apretar" más de lo habitual a un detenido que se resistía. Estos eufemismos dan cuenta de la necesidad de ocultar la violencia, algo que no era tan necesario en el apogeo de la sociedad disciplinaria. Estamos ante referencias táctiles que nos indican que la violencia es finalmente un hecho corporal que previamente persigue otras fórmulas más limpias, higiénicas, de dominación.

Sin embargo, podemos comprender la actuación de estos agentes de seguridad como la destreza profesional adquirida mediante su propia incorporación de la inseguridad. Bajo el discurso correcto del policía citado podemos encontrar un relato enterrado que emerge con dificultad. En este otro relato autobiográfico expresado con una voz más temblorosa y entrecortada, encontramos algo más de su carne, expresando así que el poder que ejerce sobre otros cuerpos procede del miedo a que sea su propio cuerpo el sometido.

Cuando entré, no temor, un poco de nerviosismo, de inseguridad, hasta que haces tu primera actuación, tu primera intervención y vas para adelante, si ves que te ha salido bien.

Existe un atisbo de verbalización del miedo propio en este policía. En el habitus policial, el miedo corporal a sufrir daños físicos por parte de los "delincuentes" parece que se va transmutando en miedo a la presión social según se va consolidando la carrera profesional. Esta presión la ejercen los medios de comunicación, los políticos profesionales, algunos movimientos sociales y en última instancia los propios jefes. El policía me habló de la escena temida y recurrente en la que tiene que decidir si "le deja en la calle o se queda detenido": la frase "Eso es muy comprometido" la emitió titubeando, temblándole la $\mathrm{vOz}$, denotando miedo o inseguridad personal al evocar dicha escena. En esta situación oral afloró lo que el discurso profesional policial no permite exhibir: la propia vulnerabilidad. Se trataba de una situación casi íntima de habla que contrasta con el ejercicio profesional en los espacios controlados por la policía. El miedo a la violencia corporal de las primeras etapas de la vida profesional se ha ido transformando en otros temores más descorporeizados, en inseguridades identitarias generadas por la presión de sus superiores, de los medios de comunicación, etc. Sin embargo, tal y como hemos podido apreciar en las referencias táctiles ("apretar"), los agentes de seguridad son el último eslabón descorporeizado en la cadena de la violencia: a partir de ellos, la violencia física será legítima si se dirige hacia cuerpos ilegítimos. Trabajan con tensión, con miedo, y ese miedo, resignificado en discurso profesional securitario, es empleado como fuerza para reproducir la violencia. 
Tanto en la sociedad disciplinaria como en la sociedad de control, las autoridades finalmente tocan los cuerpos, aunque su contacto no tiene por qué ser meramente físico, sino que se puede realizar a través del "contacto visual" o de la voz. En el CIE y la oficina de extranjería adjunta (donde se realizan diversos trámites concernientes a permisos de residencia) he podido ir observando cómo se produce toda una maquinaria de distribución de los cuerpos devaluados de las personas migrantes que acuden a arreglar sus papeles. El policía que hace el "recibimiento" a modo de primer filtro, distribuye a la gente en dos grandes grupos, que a su vez se subdividen en filas distintas de cuerpos custodiadas por guardias de seguridad privada y policías. Este primer policía, joven, no muy corpulento, con gesto serio, se comunica con monosílabos y con movimientos de cabeza y ojos que envían al visitante a un grupo o a otro. En un momento dado, cambia de actuación y recrimina a una señora de origen oriental que se ponga en la cola del primer grupo, tal y como le había indicado previamente. Predomina el silencio entre las personas que acuden a hacer sus trámites. Sólo destacan las voces de los policías que distribuyen a la gente: "Información aquí. Para trámites de residencia, ahî". El orden de este espacio-tiempo no permitiría una inversión de la situación en la que la voz de cualquier cuerpo devaluado socialmente se alzase por encima de la suya. El lenguaje policial está, además, cargado de agresividad e hipermasculinizado ("Le suda los cojones al jefe"). Las personas se mueven de un sitio para otro en función de las indicaciones y órdenes. El policía del primer filtro le dice a la chica de origen oriental "Joder, que te estoy diciendo cinco veces lo mismo!, ¡A la fila!", como si de una situación escolar se tratase.

Otro día, en el primer filtro otro policía informaba serio y eficazmente a un señor, cuando apareció por su espalda un cuerpo pequeño de mujer. Una señora de origen latinoamericano le hizo una pregunta y el policía cambió el tono, adoptando otro de enfado paternal, dejando en evidencia a la señora públicamente como ansiosa: "¡Pero espérese, no ve que estoy atendiendo a otra persona!". La señora se ruborizó ante este golpe oral de autoridad paternal que viene a sumarse a los golpes burocráticos que recibe en el recinto en una posición completamente inferiorizada. Su sonrojo facial (como si hubiese recibido una bofetada) y su sonrisa vergonzosa cercana al llanto hablaron, pero ella (como sujeto) enmudeció. Por su parte, el cuerpo del policía en esta situación sostiene una postura que significa autoridad. Respaldado por el uniforme, las armas y los compañeros, en una situación de superioridad en la información, en un espacio fuertemente territorializado, recibe cuerpos que fuera del recinto ya se encargan de devaluar las visiones hegemónicas de los medios y las redadas sistemáticas en algunas bocas de metro que contraen el espacio público y eliminan el de- 
recho al anonimato (Delgado 2007a: 11-19): cuerpos que llegan achicados, oscuros, disminuidos. Dentro del uniforme, el policía puede experimentar una sensación de poder pocas veces lograda en la vida cotidiana, salvo en el rol de padre tradicional. Actúa la paternidad con esos cuerpos achicados, infantilizados, que son ansiosos y no esperan la fila, que interrumpen cuando "el padre" está hablando. Es necesario disciplinar esos cuerpos con autoridad condescendiente, poniendo en evidencia su ansiedad e infantilidad en público, educando. La figura de poder se erige en el problema y en la solución: en eso consisten la dependencia y el control? ${ }^{7}$.

En esta situación relacional, la mujer realizaba el trámite (cada vez más restringido) del permiso de residencia. Si tiene éxito formará parte de la escala más baja de consumidores, por lo que una pequeña lección de formalidad (disciplina) encuentra su justificación. Sin embargo, aquellas personas que no podrán entrar en el disciplinamiento (porque no tienen posi-

7 Pero en ocasiones, no es sólo la Ley o el Estado quien controla e interviene sobre los cuerpos devaluados de los más empobrecidos. Precisamente, el trabajo sucio, el que no pueden hacer hoy en día las fuerzas de seguridad públicas, deben realizarlo agentes más ocultos. Elsa Blair intenta conjugar cultura y violencia como elementos que van de la mano en la ciudad colombiana de Medellín y no como opuestos (tal y como habían relacionado algunos análisis, creyendo que el exceso de violencia se daba por un defecto de "cultura") (Blair 2005: 8-10). Es así como se puede interpretar la masacre como una actuación con mensajes cifrados inscritos sobre los cuerpos. El cuerpo, signo y significante, es un potente portador de significados, y más aún cuando es cadáver. En las intervenciones sobre los cuerpos se sitúa a los mismos como un espectáculo, como un objeto puesto a distancia de un espectador. El cuerpo como texto. Y no sólo como texto: en los cuerpos intervenidos previos a su desaparición (tirándolos al río) se está jugando con la desidentificación. Un cuerpo irreconocible, sin sujeto, es un cuerpo cosificado al extremo (Blair 2005: 39-51). Las operaciones de "limpieza" de los escuadrones de la muerte en los barrios pobres de Medellín funcionan bajo esta lógica de cosificación del cuerpo, o al menos de algunos cuerpos: los de los jóvenes pobres. El proceso de conversión de la vida en nuda vida hacía posible "des-ciudadanizar", primero, y acabar con el tiro en la nuca después. El exterminio producido por los nazis no ha sido sino el ejemplo más publicitado, pero los regímenes coloniales y las actuales actuaciones de los paramilitares operan del mismo modo. Blair constata cómo en las ciudades colombianas se fue imponiendo un discurso higienista basado en los males morales (se comenzó asesinando homosexuales y prostitutas y se continuó con delincuentes, drogadictos, personas sin hogar, recicladores...). Estas operaciones están justificadas por sus victimarios por suponer una imposición del "bien" sobre el "mal" (Blair 2005: 69-71). Es evidente que la realidad de Carabanchel no es la de Medellín, sin embargo en ambos espacios funciona, aunque con distintos grados de intensidad, la lógica de la jerarquización de los cuerpos, propia de las sociedades con profunda inequidad. A pesar de las diferencias, las prácticas violentas de algunos actores, como las agresiones de los grupos de ultraderecha en barrios de Madrid, se alimentan de la misma lógica que las de los grupos paramilitares colombianos. 
bilidad de obtener residencia legal) son buscadas e interceptadas en las bocas de metro más importantes del distrito y encerradas en el CIE. En estas redadas activadas con el periodo de crisis económica, el Estado ejecuta una performance de cara a la ciudadanía consumidora, tomando cuerpo la sociedad de control que va ganando terreno a la disciplinaria.

\section{CIUDAD LIMPIA: ESTETIZACIÓN EN LA SOCIEDAD DE CONSUMO}

Hemos podido observar cómo la violencia que fluye desde arriba hacia abajo, aún siendo corporal, no siempre es física. Pierre Bourdieu se refería a la violencia simbólica como aquella que se ejerce a través de las virtudes (Bourdieu 2008: 208-211). La condición de ciudadanía, equivalente a la de elector y consumidor, implica el ejercicio de un autocontrol (no es necesario el disciplinamiento ni el control de la autoridad). Una de las formas en las que se manifiesta la violencia simbólica es deshistorizando el espacio urbano. En Carabanchel, recientemente se ha producido el derribo de su famosa cárcel, justo en el momento en que su arquitectura panóptica de opresión estaba siendo resignificada por sectores vecinales para convertirla en monumento a la memoria de los represaliados por el franquismo y el postfranquismo. Su derribo sigue una línea de intervención en el espacio público por parte de los poderes en los últimos años, consistente en la eliminación de todo rastro de alteridad, de memoria, de historia, de cuerpos de carne y hueso. Los cuerpos portadores de historia, como los de las personas empobrecidas o los de las personas mayores, son cuerpos ilegítimos en el gran festival del capital. Por ello deben ser eliminados, o al menos invisibilizados (los cuerpos de las personas migrantes sin papeles son encerrados en la nueva cárcel estetizada de la zona, el CIE, que, al contrario que la vieja prisión, trata de ocultar sus actividades al barrio; los cuerpos de las personas mayores deben entrar en dispositivos de atención, como los centros de día, o ser domesticados). Los restos orgánicos, como las hojas de los árboles caídas en el otoño, o los restos orgánicos de vida social, como los encuentros autogestionados entre adolescentes, deben ser recogidos (los servicios municipales se apresuran a dejar el asfalto limpio de materia natural y espontánea) o asimilados (como el programa "La noche más joven" dirigido a adolescentes y jóvenes para integrar su ocio en un recinto controlable y dirigido). A través de las virtudes, del otorgamiento del poder estatal en pro de sus ciudadanos, se logran otros objetivos relacionados con el control que son tan naturalizados que finalmente se transforman en autocontrol.

Las lógicas higienistas de la ciudad de consumo están estrechamente relacionadas con los dispositivos de seguridad. Pero además de constituir 
intervenciones simbólicas de poder, estas actuaciones responden a lógicas económicas de creación de nuevos mercados (especulación con los terrenos de la antigua cárcel para construir un hospital semiprivado). Quienes crean las condiciones para la inseguridad generalizada son quienes ofrecen servicios de seguridad: un mercado perfecto, el de la seguridad, que se juega en el ámbito privado y en el de la política profesional y electoral. Para que este mercado crezca es fundamental el apoyo de los medios de comunicación que hacen espectáculo con la inseguridad y distraen la atención de las causas que la originan. Los medios son una potente fábrica discursiva que genera realidad y hace considerar la misma acción como robo si se produce en las bajas esferas sociales, o libre mercado si se produce en las más elevadas. Sin ellos no habría sociedad de consumo.

Pero a pesar de la profundización de las lógicas penales e higiénicas de la sociedad de control y consumo, los cuerpos se resisten a ser dirigidos y estetizados de forma completa. A continuación expongo brevemente el marco teórico proporcionado por algunos autores y, principalmente, por Michel de Certeau por la vigencia que, según pienso, sigue mostrando para comprender por qué el control, la violencia, la inseguridad y el miedo no son determinantes en las respuestas de los agentes.

\section{UN CONTROL DE CUERPOS QUE NUNCA ES COMPLETO}

Las prácticas corporales relacionadas con el miedo no sólo se expresan de forma oral, sino que también pueden habitar en el silencio. Michael Taussig vio en la violencia estatal extrema en Colombia un régimen de silenciamiento. La guerra sucia, incluso la mera guerra, no existen oficialmente: no hay prisioneros, no hay tortura, no hay desaparecidos. El régimen de terror consiste en este silenciamiento, por lo que los silencios cobran más sentido que nunca en esos contextos (Taussig 1995: 44-46). Pese a que el entorno de la presente investigación está muy lejos del régimen de terror y violencia en Colombia, el terror más intenso sufrido en otras épocas por algunos de sus habitantes (como durante la Guerra Civil o la dictadura de cuatro décadas), la inseguridad material ("el hambre") y la hipercompetitividad contemporánea, están incorporados a las prácticas culturales a través de las memorias individuales que se transmiten de cuerpo a cuerpo. El régimen de silenciamiento sigue imperando entre buena parte de la población de Carabanchel que considera que lo político sólo puede ser política profesional.

¿En qué "no lugares" habita o se desplaza la subjetividad de quienes no han alzado la voz? Si lo que apunto es válido, el miedo es otra cosa distin- 
ta de lo que pretende representar el discurso de la inseguridad (significante): la cosa otra (alteridad internalizada) que habita en el cuerpo, que condiciona las prácticas y que es fruto de las exclusiones sufridas e incorporadas. El miedo a la pérdida, el miedo al público, el miedo a la soledad, el miedo a la interacción, el miedo a no estar a la altura, el miedo a la complejidad, etc. son miedos silenciosos que se relacionan sólo de manera mínima y oblicua con el miedo al entorno, a la ciudad, a la delincuencia (a pesar de que el discurso hegemónico de la inseguridad focalice la atención sobre estos últimos). Se trata de explorar lo que anda suelto, porque no está sujeto (a una identidad, a un discurso): observar el miedo en su sentido corporal y práctico.

El "no sujeto" o "sujeto-suelto" habita en un no lugar, es cualquiera, sin identidad (no la ha construido ni afirmado). En el trabajo, entre las amistades, en la familia, en los conciertos, en las aulas, en los campos de fútbol, "es", pero cuando sale, simplemente "está". En su soledad silenciosa, no se siente interpelado. Y sin embargo, es agente. Si se pronuncia puede ser dominado. Quizás el "sujeto-suelto" tiene miedo a algún tipo de dominación (más que miedo a la "delincuencia"), pero el miedo no le bloquea (como interpretarían algunas psicologías): le acompaña y le ayuda a moverse, también a crear, a vincularse y a desafiliarse. No todo es dominación en el miedo; no todo es pasividad en el silencio. Las desapariciones de personas en barriadas como la observada por Nancy Scheper-Hughes en Brasil es algo previsto por sus moradores, lo cual convierte en rutinarias las pérdidas de seres queridos y denota la devaluación social del cuerpo de los miembros de las clases populares. La cultura del silencio y del miedo, resultado de las condiciones de opresión que sufren los habitantes de las barriadas pobres de Bon Jesús (asimilada por Scheper-Hughes con una "institución total"), dificulta la existencia de sujetos sociales. Pero para la autora, estas dificultades propiciadas por la dominación no exterminan la capacidad de negociación de estas clases oprimidas: las tácticas de resistencia (de Certeau), o simplemente de existencia, nos informan de la supervivencia de una agencia en las personas que sufren situaciones extremas de violencia estructural y simbólica (Scheper-Hughes 1997: 506-509).

El habitar del miedo está en el cuerpo. En su Antropología del cuerpo, Mari Luz Esteban despliega una mirada sobre el mismo como agente social. Acudiendo a Thomas Csordas y su concepto de embodiment, el cuerpo no es reconocido ya sólo como espacio en blanco sobre el que se inscriben los procesos sociales, sino como parte material activa en la construcción de esos mismos procesos. El cuerpo pasa a ser, entonces, un espacio en el que está encarnada la estructura social pero que a su vez ejerce como agente de la construcción social, reproductor de esa estructura y resistente a la 
misma (Esteban 2004: 19-27). Los itinerarios corporales constituyen rutas de empoderamiento y desempoderamiento que, por lo que he observado, están estrechamente relacionadas con el miedo (mucho más que con la "inseguridad ciudadana").

Estos itinerarios corporales se realizan a través de prácticas de espacialización. Según el análisis realizado hace ya tres décadas por Michel de Certeau, el panóptico no puede ser omnisciente. Al verlo todo, aprehende poco. Lo inasible, lo íntimo, lo ágrafo, escapa, a veces, por las sombras, por las áreas ciegas que el propio foco propicia. Otras veces, el foco alumbra tanto que ciega al propio vigilante. En ese instante se producen movimientos, se avanza en la construcción de los túneles y hasta se producen abrazos. Los cuerpos que se abrazan no se ven, sino que se transmiten un saber que no puede ser capturado. Tal y como señala Michel de Certeau, "el conocimiento ciego del cuerpo a cuerpo amoroso" (de Certeau 1996: 105) constituye una práctica de espacialización. Voy a tratar de relacionar esas prácticas de espacialización y otras vinculadas a lo oral con el miedo urbano. El hecho de profundizar en la obra de Michel de Certeau me proporciona la oportunidad de adentrarme en el miedo íntimo que se practica cotidianamente. Se trata, entonces, de situar la atención ya no sólo en el discurso elaborado, sino también en el cuerpo (un cuerpo que habla y ca1la). El silencio que suele acompañar a este miedo de la vida cotidiana no puede interpretarse únicamente como inhibición pasiva: al contrario, parto del papel activo del silencio. Para ello me sirvo de algunas nociones que lo interpretan como una ausencia de palabra abierta a múltiples significaciones, y entre ellas no descarto la que se refiere al hecho de negarse a hablar como una forma activa de resistencia (Ramos 1996: 4). ¿El sonrojo de la señora que preguntó "inoportunamente" al policía en la "oficina de extranjería" puede leerse como una actuación de resistencia ante un régimen de ruptura del cuerpo individual y social? Quizás la rabia se hizo sangre, carne roja, explicitando la relación autoritaria sin decirlo (pues la escena se jugaba en "el lugar del otro"): no es sólo un quieto sometimiento del miedo "paralizante" a la autoridad, sino también táctica de supervivencia que expresa callando (y quizás genere actos de resistencia más amplios). Si el golpe verbal del policía puso en evidencia a la mujer como ansiosa, su silencioso sonrojo evidenció al policía como autoritario y deslegitimó su "razón”. No habló un sujeto, sino que actuó un cuerpo.

Quiero añadir aquí una aclaración conceptual sobre la separación conscientemente artificial que realizo entre oralidad (como práctica corp-oral) y discurso a la hora de analizar el material etnográfico. Es evidente que esta separación es artificial: la cultura oral popular ha bebido de discursos de poder, apropiándose de ellos, e inversamente, los discursos de los expertos 
se apoderan de las narraciones orales. Sin embargo, siguiendo la distinción establecida por de Certeau entre discurso (orden escriturario) y oralidad (orden corporal), podemos encontrar diferencias en la intensidad emocional de la emisión. Esta intensidad, que se manifiesta a través de la corporalidad (la forma de hablar, de gesticular, los rasgos que adopta el cuerpo en cuanto al riego sanguíneo, la respiración, la postura, etc.) es diferente según se pretenda un objetivo estratégico en el acto de habla (como puede ser conseguir un beneficio material o simbólico) u otro táctico (menos consciente y elaborado, más espontáneo, aprovechando lo que viene dado para hacer "salir" ciertos pensamientos y emociones). Se trata de un continuo de posiciones muy variable a lo largo de una conversación, por lo que es difícil encontrarlas en estado puro. Tampoco trato de dividir entre actuaciones estratégicas y expresiones de las emociones internas, tal y como se haría desde enfoques de corte psicologista: considero que tanto los actos de habla estratégicos como los tácticos son actuaciones performativas de superficie (Butler 2007b: 264) de determinadas posiciones sociales (de clase, género...) y de roles conversacionales, pero sin embargo podemos detectar cómo algunos están más incorporados, sedimentados, naturalizados e impensados que otros, es decir, "mejor" actuados. En esta brecha entre lo más incorporado (el miedo) y lo más elaborado (discurso de la inseguridad), es donde encuentro contradicciones en lo que dicen los vecinos de Carabanchel. Entre sus prácticas discursivas (ahora ya entendidas como enunciaciones estratégicas que tratan de ocultar el propio cuerpo) y sus prácticas orales (más inconscientes, tácticas y corp-orales): en un lado coloco, sólo como tipo ideal que ayude al análisis, los discursos, y en el otro, las prácticas corporales (la oralidad activa y las acciones silenciosas del cuerpo en la vida cotidiana).

\section{DISCURSO DE LA INSEGURIDAD}

El control policial y el higienismo urbano, como mecanismos aludidos más arriba de gestión de los residuos que pueden infectar el buen funcionamiento del orden en sociedades tan opulentas como desiguales, encuentran un complemento en el abono ideológico proporcionado por los medios de comunicación. El mensaje televisivo de la inseguridad puede afectar de modos diferentes. Por un lado puede incorporarse y sedimentarse en forma de miedo ("Yo no voy a dejar el niño con cualquiera [...], el niño es mi vida, con todo lo que se oye ahora") y, por otro, puede ser apropiado para elaborar un discurso estratégico desde abajo (oralizado) en situaciones de competencia por recursos sociales escasos: el discurso de la inseguridad 
se emplea habitualmente para deslegitimar al competidor $^{8}$. La ficción televisiva supera a la experiencia propia en la organización de la vida cotidiana. El sistema experto y sus dictados de visión y división parecen sustituir a la propia experiencia, principalmente en procesos de desempoderamiento y aumento de la dependencia de figuras de mayor poder (como en el caso de muchas personas mayores cuyo cuerpo pasa a ser custodiado por expertos en la atención sociosanitaria) (García García 2008). Pero quizás, más que ante una sustitución nos encontremos ante una elección de las fuentes de información y los argumentos que mayor coherencia muestren respecto a su posicionamiento en sus luchas horizontales en la escasez.

Los discursos de la inseguridad no dan cuenta de una realidad objetiva ("el aumento de la inseguridad"), sino de posiciones subjetivas ante el mundo social. Como discursos, tienen una dimensión estratégica que, aunque puedan ser enunciados oralmente, los sitúa en el orden de la escritura. Se trata de dicciones articuladas de manera "correcta", generalmente en tercera persona (o en primera persona cuando se trata de exhibir las propias virtudes), emitidas desde las agencias políticas profesionales, instituciones y demás centros de poder (medios de comunicación). El lenguaje escrito es el empleado preferentemente por los sistemas expertos. Ésta es la lógica que determina los discursos de la inseguridad. Podemos encontrar una interpretación común de la modernidad (y su post- o tardo-) como una época en la que el presente espontáneo e instantáneo en la comunicación queda desplazado (habita un no lugar). En la medida en que se acortan las distancias globales, aumenta la necesidad de sistemas expertos que tramiten la información. Es así como la escritura (también en su versión digital contemporánea) ha podido imponerse de una manera tan abrumadora sobre la narración oral cuerpo a cuerpo: la "escritura que invade el espacio y capitaliza el tiempo” (de Certeau 1993: 212) lo hace en función de su carácter representativo. El miedo, la sensación íntima de incertidumbre que parece

${ }^{8}$ De Certeau establece una diferencia entre estrategia y táctica: la estrategia es "el cálculo (o la manipulación) de las relaciones de fuerzas que se hace posible desde que un sujeto de voluntad y de poder (una empresa, un ejército, una ciudad, una institución científica) resulta aislable", esto es, se instala en un lugar, algo propio, desde el cual maneja las relaciones con una exterioridad de metas o de amenazas que es posible a partir de la vista panóptica. En contraposición, táctica es definida por de Certeau como "la acción calculada que determina la ausencia de un lugar propio" y que se efectúa en el lugar del otro (o en un no lugar), bajo su lenguaje, su ley, sin acumular nada pero aprovechando las "ocasiones" y llevando a cabo escamoteos, estratagemas, trampillas, sorpresas (de Certeau 2007: 40-45). En este caso, la estrategia es trazada desde abajo: estamos ante un discurso estratégico (el de la inseguridad) apropiado por alguien del mundo popular que lo oraliza y lo emplea en sus luchas de poder locales. 
habitar en todas las personas, aunque con intensidades y significados diferentes en momentos distintos, es transformado en palabra. Esta palabra se instituye en lugar del otro, tomando un significado diferente del espíritu inicial que dio lugar a la actuación del miedo (de Certeau 1993: 204). El discurso de la inseguridad ha sido reforzado en los últimos años en el Estado español, principalmente en las grandes ciudades, por las instancias representativas (los sistemas expertos de las democracias parlamentarias) como forma de legitimación del poder de los expertos de la política profesional y el mercado.

Pero quizás, este "nuevo" fenómeno no sea sino la reactualización de un viejo problema. Tal y como señala de Certeau, en el S. XVII se produce una dispersión de los cuerpos que introduce las disciplinas de su sujeción. Esto es posible gracias a la búsqueda de certezas por parte de unos sujetos que previamente se sentían inseguros (de Certeau 1997: 6). Así como la inseguridad de los sujetos propició la seguridad social del Estado moderno, el retorno actual del pensamiento hobbesiano sólo es posible si existe un público receptor que deja de serlo y se apropia de nuevo de los propios discursos, no tanto para legitimar el poder represivo del Estado, como para legitimarse en las propias luchas sociales en los distintos campos de los que forman parte las personas en las sociedades contemporáneas (laborales, de consumo, culturales, sexuales, etc.). Se produce así una resignificación del discurso hegemónico que no es automática, sino táctica, práctica y creativa. Este discurso, aunque estereotipado, es reinventado, reintroducido en el mundo de los relatos.

Este discurso de la inseguridad reapropiado puede ser un acto de reproducción del orden, pero efectuado desde cierta agencialidad: trazando estrategias de pequeña escala (casi tácticas) para sobrevivir en un medio competitivo. Es así cómo varias mujeres de etnia gitana me comentaron, siendo trabajador social en el distrito", que no querían que sus hijas asistieran al instituto de secundaria el curso siguiente. El motivo que aducían es lo poco preparadas que estaban sus hijas ante los peligros que acechan en los institutos ("drogas", "acoso escolar", "litronas"): "lo dice todo el mundo, lo dice la tele", "en la puerta del instituto te lo cuentan los padres", "la calle está muy mal". Una de ellas refirió que temía cuando su hija salía a la calle, ya que es "muy guapa, casi modelo, y con toda esta extranjería...". Lo que parece haber como preocupación de fondo es miedo a la pérdida

\footnotetext{
${ }^{9}$ Esta etnografía parte de mi empleo como trabajador social en los servicios sociales municipales de Carabanchel durante una década. La exposición a los miedos y los discursos de la inseguridad de algunas de las personas con las que trabajaba me hizo interrogarme acerca de sus condiciones sociales de aparición.
} 
de control social sobre los hijos y las hijas en un espacio de umbral ("el instituto"). Los pánicos morales se dan cita en el espacio escolar, principalmente a la salida de clase (en el espacio-tiempo de tránsito entre la institución escolar y la familiar). En otra entrevista, una mujer mayor afirmaba que en su portal "hay miedo" (en tercera persona), enunciando este discurso en tono de broma ( $\sin$ actuar el propio miedo corporal) y tratando de hilarlo con el argumento "es que vienen en un plan" (los "de fuera"). Los vecinos extranjeros que sustituyen a sus viejos vecinos afines son amenazantes en la medida en que han avanzado en esa posición de umbral (ya están dentro del portal): pueden arrebatarles poder. Considero que estamos ante discursos de la inseguridad anti-otros reapropiados con fines estratégicos, pues no es tanto el miedo a la violencia delincuencial como a la pérdida de poder social lo que está en juego.

Aunque los discursos citados han sido enunciados por mujeres, en ellos podemos encontrar las marcas de lo simbólicamente masculino en la conformación de identidades. Tal y como lo interpreto, el orden del discurso pertenece al polo masculino del binario simbólico de sexo/género vigente durante la modernidad (Serret 2004). Desde esta perspectiva masculina, más que tocar, se ve. Parece que en el orden del discurso se exponen los propios capitales, tanto se hable de seguridad o de inseguridad. Un cura y un policía (ambas son figuras masculinistas con autoridad en el barrio) mantenían un discurso sobre la creciente seguridad en el entorno. Esta seguridad se debía a su propia presencia, a su labor, a pesar de "los extranjeros", "los gitanos", "los yonquis" o "las bandas latinas". En esta exhibición de los propios capitales por medio de un discurso ambiguo de la (in)seguridad (desde su posición hay motivos para estar inseguros en Carabanchel, pero su actuación es muy positiva, casi heroica, y logra reducir los riesgos), intentaron ejercer un fuerte control sobre la situación corporal del encuentro conmigo. Ambos eligieron la posición física en la que hablar (la posición de mi cuerpo con respecto al suyo y la posición de nuestros cuerpos con respecto al resto del recinto) y controlaron el registro de la conversación (lo que debía grabarse y lo que no). Desde un discurso opuesto, otros dos hombres en posiciones de desempoderamiento social (uno con cáncer, el otro envejecido, ambos con menos capital económico y social que en el pasado), sostenían un discurso sobre la creciente inseguridad en el barrio a modo de evaluación panóptica (no en primera persona, sino en formas impersonales), pero ejerciendo también control sobre la corporalidad y la oralidad, que no debían delatar ninguna debilidad en primera persona. Según su argumento, la "gente" del barrio tendría razones para tener miedo, pero se excluyen de la noción de "gente" a la hora de hablar de emociones relacionadas con la vulnerabilidad ("El barrio está muy mal [...]. No, yo no tengo miedo"). 
Se trata, entonces, de discursos elaborados, más o menos estereotipados, que informan mejor del posicionamiento identitario de sus emisores que de sus emociones y sus prácticas en la vida cotidiana. En estos discursos con rasgos de masculinidad tradicional es en los que podemos encontrar una mayor brecha entre lo que se dice y lo que se hace. Mediante estos discursos colectivos pueden construir performativamente la comunidad de los inseguros (comunidad sucedánea pero que se convierte muchas veces en un sujeto político cuyas demandas son toleradas y ampliamente respaldadas por las autoridades, endureciendo códigos penales o aumentando las plantillas de policía). Su origen (arriba) es estratégico, pero su consumo (abajo) comienza a ser táctico.

\section{MIEDO EN LA ORALIDAD}

A continuación voy a tratar de desarrollar en qué se van concretando las tácticas en relación a la (in)seguridad. El orden del discurso constituyó durante los primeros pasos de la investigación el objeto privilegiado para una hermenéutica de lo que "se dice" sobre la inseguridad en Carabanchel, pero a medida que avanzaba iba intuyendo la existencia de desajustes entre los discursos referidos al entorno y a la inseguridad y las prácticas concretas. Fue emergiendo la idea de ir más allá de unos discursos "públicos" condicionados por mi propia presencia cargada de significados para los informantes (como investigador social, como trabajador social del distrito, y a veces hasta como imaginado periodista). Aquí estriba, en mi opinión, el valor de la obra de de Certeau para una antropología del miedo, que no es sino una antropología de la vida cotidiana: el conocimiento que no está en los discursos, sino en los relatos (prácticas orales), informa del mundo de las emociones y la memoria atávica excluida de la Historia (Cassigoli 2007: 104).

Aunque, tal y como he señalado más arriba, el discurso (del orden de la escritura) sea reapropiado y retorne a la enunciación oral, hay otro tipo de prácticas corporales que actúan el miedo y que proceden de la memoria colectiva. El miedo no se exorciza por la aparición de un otro (inmigrante, joven, nuevo pobre) sobre el que cargar la responsabilidad de las propias incertidumbres: los discursos de la inseguridad que buscan un chivo expiatorio son estratégicos en la conformación de identidades (nacionales, étnicas, etc.), pero no parecen aliviar la sensación de temor. Se podría afirmar, sin embargo, que las incertidumbres tienen que ver más con otros miedos que proceden de la remota infancia (como las primeras experiencias de separación de quien alimenta) y con su reactualización continua a lo largo de la vida en forma de desasosiego por la pérdida de anclajes en 
un mundo hipercompetitivo (en el mundo laboral, afectivo, etc.). Tal y como analicé en una primera etapa del trabajo de campo en Carabanchel, la sensación íntima de miedo parece encontrar mayores posibilidades de manifestarse entre las personas que habitan el barrio en aquellos momentos vitales en los que la autonomía decrece (desempoderamiento). Es en estos momentos personales cuando el discurso de la inseguridad (procedente de los medios y de las voces vecinales autorizadas) parece retornar a lo oral y se transforma en fantasía, penetra en el imaginario cotidiano y pasa a condicionar prácticas. Nos vamos acercando desde el discurso a lo oral y a lo corporal.

Las narraciones del miedo pueden ser definidas por aquello que se dice en relación al temor propio y a la confianza en el entorno. En primera o segunda persona, estas enunciaciones parecen traicionar menos las propias emociones corporales que los discursos: son más consecuentes con la propia experiencia. Parecen emitirse desde el polo femenino del binario de sexo/ género, ya que es desde éste, y no desde la actuación de la masculinidad, donde se exhibe la propia vulnerabilidad. Una mujer joven expresaba: "Ya no cruzo de noche el parque" (por temor a una agresión sexual). Por su parte, unas mujeres mayores residentes en viviendas unifamiliares referían como situaciones de temor "Me han pintado la pared" o "Me han entrado" (en casa): la casa de estas mujeres de la diminuta burguesía que vive en el distrito, socializadas en el rol de depositarias de lo doméstico, parecían identificar su casa con su cuerpo.

En las narraciones que parecen expresar fidedignamente la experiencia corporal, se proporcionan imágenes del propio cuerpo y del de los otros que asustan. Otra mujer mayor, ésta habitante de unas viviendas obreras, expresó lo siguiente:

Hay veces cuando veo en la calle, cuando veo el grupito así, me da... [...] De personas de gente así que está, para mí, que los veo que no, y sobre todo, no, no, de verdad, he cogido miedo a lo extranjero [...].

La noción de inseguridad que manejaban esta mujer y los vecinos con los que me entrevisté mezclaba el temor sentido ante la presencia de nuevos vecinos jóvenes de origen extranjero, con el miedo al robo, con lo indeseable de sus gustos musicales y con la presencia de "bichos voladores". El miedo íntimo se relacionaba con la cercanía de la alteridad, siempre amenazante para una identidad que ya de por sí está debilitada. En este caso, la debilidad se producía como consecuencia de la pérdida de aquello que les dotaba de cierta autonomía: la vida laboral y la familiar. El cumplimiento de los objetivos del proyecto vital preponderante entre aquellas familias migrantes que conformaban la clase obrera periférica de la época fran- 
quista quedaba atrás. Una mujer residente en la misma calle, que además realizaba la limpieza del portal, manifestó que siempre tuvo muy buenas relaciones con los vecinos ("Sacaron la cara por mí cuando el presidente de la comunidad estafó y se quedó con mi sueldo"). Echaba en falta la vivencia comunitaria del pasado: ahora son "extranjeros" quienes han sucedido a los autóctonos fallecidos. Se quejaba de los pasos, de los continuos movimientos de gente: de la presencia de sus cuerpos ilegítimos en el espacio. El desempoderamiento de estos pensionistas era también corporal, y ante la pregunta de si antes no sentían la misma inseguridad, una de las vecinas respondió: "sí, pero tenía mejor las piernas para correr". Por su parte, otra comentó: "tengo miedo a que me empujen y me tiren al suelo en la calle". Según interpreto, los cambios del propio cuerpo van asociados a la pérdida de poder social y ligados al deterioro del cuerpo comunitario.

Los relatos orales del miedo suelen expresarse en primera persona o en referencia a personas cercanas (temores sentidos hacia el entorno próximo, información sobre prácticas propias para prevenir situaciones de robo o agresión...) o en forma de recomendaciones de precaución ("no vayas por esa calle"). Una mujer joven refería que ella, a diferencia de su marido, ya no practicaba la venta ambulante al temer la aparición de la policía, que era más persistente, según indicaba, desde que estaban los "manteros": "Desde que se ponen los chicos con los CDs, no nos dejan en paz [...]. Siento miedo, mirando para todos los lados". La presencia de cuerpos más ilegítimos que el propio (un cuerpo de una mujer "gitana") junto a ella, ponía en peligro la obtención de recursos y la propia integridad. Pero además, si lo que postulo es válido, en estas enunciaciones orales encontramos una actuación performativa de los vínculos personales y vecinales a partir de la expresión de las propias emociones. No se trata tanto de alocuciones estratégicas (ganar una posición de poder) como tácticas (sobrevivir con lo justo, ingeniárselas con lo que viene dado y vincularse más horizontalmente).

Por cierto, uno de los manteros de origen africano de una calle comercial de Carabanchel empleaba, probablemente como estrategia disuasoria, una bandera de España en su cazadora militar esperando con ello repeler agresiones policiales, racistas y clasistas, y atenuar, así, las diferencias que les hacen más vulnerables (menos ciudadanos): los símbolos de la indumentaria pueden proteger al propio cuerpo. Vamos acercándonos a la relación entre actuaciones corporales y miedo.

\section{PRÁCTICAS CORPORALES DEL MIEDO}

Como he adelantado, el miedo propio puede reforzar el orden, pero también ser motor de sociabilidad. Una historia de miedo o una llamada a 
la precaución, más allá de su contenido paralizante, pueden servir para vincularse. Una señora mayor dijo en la calle a una madre y su hija: "¡Uh, qué niña más bonita! Hay que tener cuidado con todo lo que pasa hoy". Hay discurso ("lo que pasa hoy" es lo que transmite la televisión que pasa hoy), hay apropiación del discurso que se lleva a la oralidad (no se emite desde ninguna posición de poder estratégica), pero además hay una actuación del encuentro cuerpo a cuerpo (hay táctica) que rompe la atomización. Se instrumentaliza el discurso dominante para efectuar una interacción en el barrio que de otro modo no encontraría excusa.

A pesar de la observación de prácticas concretas y de la escucha acerca de lo que se hace en la vida cotidiana (en entrevistas o en las conversaciones captadas espontáneamente en la calle), considero que ésta es la parte más compleja de mi trabajo. Sigo reflexionando sobre si es factible observar etnográficamente el miedo en el cuerpo ajeno silencioso. El silencio solitario lo es si se observa desde fuera a la persona, pero dentro puede habitar el ruido de los diálogos internos o las voces irritantes. Por ello, su captación requiere de una afinada observación. Manuel Delgado remite a Michel de Certeau cuando afirma que a través de los discursos conocemos las hegemonías y a través de las prácticas accedemos a los escapes, las resistencias ("A ras de suelo las cosas se complican siempre") (Delgado 2007b). La noción de espacio público para este antropólogo es la de espacio del silencio, en el límite entre comunicación y no comunicación, el del "derecho a la indiferencia" (ya no sólo a la diferencia). No se trata de un espacio público sólo para el encuentro, amable, sino de un espacio donde hay conflicto, complejidad, negociación. El miedo está ahí, aunque a veces también se cuela por las rendijas de las puertas y las ventanas.

El miedo viaja en los cuerpos y, como molde de escayola, limita los movimientos a la vez que los acompaña. El miedo puede ser la alteridad no reconocida, no legitimada, que habita en las subjetividades: el ruido que no se quiere oír y que no para de hablarnos en forma de voces introyectadas o las imágenes violentas que dejan impronta. Habita en un no lugar: un espacio en el que no se efectúan identidades, discursos o estrategias, sino tácticas con las que los agentes se desenvuelven en la vida cotidiana. Ejemplo de las prácticas relacionadas con el miedo que observo son los recorridos rutinarios "seguros" escogidos por los actores en el barrio, las precauciones tomadas antes de salir de casa, el uso del coche para moverse por la ciudad, la forma preventiva de estar en el espacio público (la mirada, la manera de caminar) o el consumo de artículos destinados a preservar la seguridad.

A partir de lo que vengo observando, resulta difícil extraer una tipología clara de actitudes corporales en relación al miedo. Todos los informantes 
entrevistados tienen comportamientos variables en el tiempo, todos sienten algún grado de miedo y al mismo tiempo algún grado de seguridad y confianza. En un barrio representado como peligroso por su composición de clase y por la presencia de la cárcel, como Carabanchel, cabría esperar un vaciamiento del espacio público. Sin embargo, se puede afirmar que sus espacios públicos son usados por muchas personas, incluso las que se sienten más vulnerables (mayores). Es la concurrencia densa de alteridades en este espacio la que quizás haga aflorar discursos sobre su peligrosidad, pero son sólo eso, discursos. Pese a que la llegada al barrio de un elevado número de población extranjera en la última década despertó multitud de situaciones de desconfianza que se podían observar en lo que se decía (discursos y narraciones de caos, desconfianza) y en lo que se hacía (proliferaron los sistemas de seguridad en comunidades de vecinos), en la última exploración de campo me encuentro con un uso de los espacios que no ha variado en intensidad. Las personas mayores, con sus cuerpos históricos, siguen saliendo y relacionándose, a veces con personas más jóvenes autóctonas y de origen extranjero. Hay miedo y hay confianza.

Pero mi propio cuerpo, actuando sus miedos de manera diversa, también me obliga a observarme. Esta etnografía de lo íntimo persigue el encuentro con lo "éxtimo" (extraño dentro de uno mismo) ${ }^{10}$, y por ello considero honesto explicitar un pasaje de mi propia experiencia corporal haciendo trabajo de campo. Al día siguiente de haber vivido una situación de tensión, en la que fui increpado por tomar unas fotos a la salida de un colegio (ese espacio de umbral lleno de pánicos morales alrededor de la infancia) y sentí miedo a una agresión, acudí a Carabanchel con sensación de ir "contraído". El miedo suele asociarse con opresión corporal, encogimiento. Ese día no me atreví a hacer fotos. Mis pensamientos eran de continuo cuestionamiento ético de mi actividad, mi atención a lo que ocurría en la calle se veía reducida por el enorme ruido interior que para el exterior era mero silencio. La llamada de atención que supuso el conflicto en la puerta del colegio se -me- incorporó a modo de autocontrol. Mi impresión era de ilegitimidad en las calles de Carabanchel, sintiendo que todos los viandantes sospechaban de mí, con sensación de culpa y soledad. Una respiración corta y una masa sobre mi cabeza, sobre mis ojos, me hacían perder atención, presencia, espontaneidad. Sólo un encuentro corporal y oral horizontal, de reconocimiento mutuo con una persona apreciada por mí, pudo "qui-

${ }^{10}$ Francine Masiello emplea un concepto inventado por Lacan, lo éxtimo, para referirse a las posibilidades abiertas que brinda el espacio público al producirse el encuentro con lo extraño que cada persona lleva dentro (la alteridad negada), al no existir identidades acabadas (Masiello en comunicación personal, 2008). 
tarme ese peso de encima". Y es que el miedo, la culpa, la ilegitimidad, todos ellos asociados, pesan. No creo que nadie lo notase, y menos otro etnógrafo.

Consciente de las limitaciones para observar el miedo actuado silenciosamente, puedo aproximarme, sin embargo, de manera elíptica a través de la observación y la escucha de los cuerpos que dan miedo. El miedo es algo que se trata de disimular en los espacios públicos "porque se huele", dicen, y transmitir que se tiene miedo es estar a merced de un agresor. Se usan, así, "desodorantes sociales"11 que puedan disuadir a los presuntos agresores. Sin embargo, quienes en las entrevistas son los más repetitivamente señalados como agentes de miedo saben jugar con ello. Ellos también tienen miedo (por la exclusión incorporada y por la fuerte competitividad en la que se desenvuelven), pero su cuerpo ha aprendido a efectuar tácticas para sacar provecho de su posición subordinada y, en ocasiones, han capitalizado la desconfianza mutua para transformarla en una estrategia de obtención de beneficios económicos y simbólicos. Observando sus prácticas espaciales podemos localizar las prácticas complementarias de quienes sienten miedo. Unos hombres con estilo "yonqui" se valían de su estigma corp-oral (marcado en sus caras, en sus ropas y en su habla) para ocupar de manera exclusivista el parque en el que se encontraban (los cuerpos distantes se hablaban en voz alta, ocupando sonoramente buena parte del parque, con el resultado de que nadie más se atrevía a estar en esa área). Por su parte, unos limpiadores de cristales de un semáforo se servían de su aproximación a los cuerpos solitarios y preventivamente a distancia en el interior de los vehículos y contactaban con su cepillo con el cristal y el acero de los mismos, consiguiendo generar vulnerabilidad y nerviosismo en sus conductores en alerta: el pago al limpiador por parte de estos conductores era la compra de su tranquilidad. En otra ocasión, un joven me contaba cómo él se sentía muy tranquilo gracias a que su cuerpo gitano daba miedo. Lo mismo expresaban varios adolescentes entrevistados que referían que sus pintas hacían asustarse a algunas personas.

Podemos interpretar estas corporalidades como usos tácticos de la exclusión que sufren, convertida en fuente de miedo, aunque en la medida en que estas interacciones corporales van siendo reflexionadas, se van transformando en palabra, en oralidad, y en algunos casos, como en el de los "gitanos cuidando la obra", en estrategia (ofreciendo seguridad). La agencialidad se ejerce desde el cuerpo.

\footnotetext{
11 Debo la metáfora a la compañera antropóloga Virtudes Téllez.
} 


\section{MIEDO Y AGENCIALIDAD}

Hasta aquí hemos recorrido las distintas actuaciones de la inseguridad y el miedo: discursiva, oral y corporal. A continuación vamos a poder apreciar cómo los agentes se apropian de estas situaciones, las resignifican e inventan nuevas formas de relación. Hemos visto en el apartado anterior que dar miedo es una forma, quizás la más desesperada, de ejercer poder (una suerte de capital corporal donde faltan otros capitales). Igual que los aparatos de poder, se valen del uso del miedo a la alteridad, a lo que ensucia la identidad, higienizando el barrio, esos autores de la suciedad tienen su propia respuesta: corroboran la inseguridad con su presencia amenazante. No rebaten el discurso de la inseguridad, sino que lo alimentan pero desde otra posición, desde el "lado malo" que mencionó un adolescente refiriéndose a la propia posición de Carabanchel en el imaginario social. Estamos ante un uso activo del miedo por parte de los construidos como peligrosos por el discurso. Las luchas por el reconocimiento del bautizado por Lefebvre como derecho a la ciudad son el resultado de prácticas informales. Es así como podemos concebir la estética transgresora, la producción cultural, los espacios apropiados e incluso la violencia desarrollada por algunos sectores como la forma de negociar con lo que se tiene, que principalmente es el cuerpo, cuando otros capitales son negados (Naranjo et al. 2001: 97-100). Incluso la moral desarrollada por los sectores y subsectores populares, aún siendo conservadora o reproductora de la violencia y de los intereses de los dominantes, constituye una forma propia de participación política.

Pero existen otros usos posibles del miedo íntimo por parte de quienes lo padecen. Así, donde más miedo parece haber, en los espacios y los tiempos de umbral, es donde se producen con mayor intensidad las resignificaciones y se juega la confianza. Una escena cotidiana en un cajero automático en el que una señora mayor sacaba dinero mirando de un lado a otro, cambió al llegar otro señor y colocarse detrás de ella a una distancia "prudente" para que no se asustase. El gesto del señor supuso la recuperación de la confianza en ella. Otro ejemplo de transformación de una situación de vulnerabilidad en otra donde se ejercita cierta autonomía lo constituye el cronotopo de la salida del colegio, que se llena de padres y madres que practican así su temor a perder el control físico y moral sobre sus hijos en el espacio público (no institucional) y se acaba convirtiendo en un momento de sociabilidad que se trata de alargar y en el que las asociaciones más o menos espontáneas que hacen entre sí los infantes sirven a sus responsables para interactuar cara a cara fuera de sus propias instituciones (laboral y familiar). 
Por último, una suerte de resistencia a lo prescrito son las prácticas de espacialización y sociabilidad llevadas a cabo incluso por personas que se sienten vulnerables, con miedo. El barrio atomizado que separa cuerpos (en urbanizaciones cerradas en la parte más nueva del distrito, con calles anchas para la circulación de los coches, manzanas cerradas con seguridad privada, etc.), que así se hacen más dependientes del mercado y de las instituciones, se desatomiza cuando sus vecinos buscan espacios de sociabilidad no mercantilizada y no dirigida en los parques externos a las fincas. Una vez más se emplea el pretexto de los niños y otro que parece ganar fuerza, el de "sacar al perro": la interacción más espontánea entre los cuerpos de los niños, y sobre todo de los perros, ayuda a los cuerpos de sus responsables, adultos humanos, a acercarse, a hablar, a reírse y a veces a tocarse. El perro no sólo proporciona seguridad y afecto, también sociabilidad.

Pero quizás un paso más allá en la resignificación del miedo, la inseguridad y la desconfianza, sea la reflexión sobre la misma a través del propio habla. Esta reflexión consigue atenuar el temor y se efectúa partiendo del polo femenino del binario de sexo/género. Hablar de los propios miedos, asumiendo la propia vulnerabilidad, es reconocer que existen temores incorporados que quizás no tengan tanta relación con la supuesta peligrosidad del entorno que los discursos hegemónicos transmiten. Una mujer de 35 años que entrevisté por primera vez en 2005, manifestando entonces pánico hacia el barrio y mostrándose muy vulnerable ante los mensajes televisivos de sucesos, reconoció casi cuatro años después que en su propia percepción afectaba su relación con el barrio y su inseguridad vital al ser entonces madre primeriza. Ahora que hablaba con otras personas de su zona, es decir, que tenía una experiencia social directa, sin mediaciones, transmitía una visión algo más amable de su entorno: la experiencia directa supone autonomía. Otra mujer mayor transmitió en un tono reflexivo que desde que quedó viuda se había encerrado y se sentía "como si estuviera en una cárcel”. Otra, sin embargo, hablaba de su identificación con el barrio en los últimos tiempos en que salía más tras sufrir la muerte (por causas naturales) de tres de sus hijos y de su marido en pocos años y varios robos en casa. El levantamiento de un muro de 6 metros de alto alrededor de su vivienda por parte de su único hijo superviviente no parecía ir con ella (era algo de su hijo) y aprovechaba la salida "a la compra" para quedarse en el parque hablando con varias conocidas, algunas de ellas "extranjeras". Por su parte, otra comentó su resistencia al nuevo modelo de vivienda en manzana cerrada de esta forma:

Mis hijos querían que viviese con ellos en su casa, pero me asomaba a la ventana y solo veía la piscina a un lado y un parquecillo para los niños al otro. Yo prefiero mirar a la calle, ya conozco a la gente que pasa, "ahí va fulanito". 
La reflexividad y la sociabilidad, esto es, la integración de los discursos, el habla y la corporalidad, son capaces de combatir la sensación de vulnerabilidad. Para Mari Luz Esteban, todo empoderamiento social es empoderamiento corporal (Esteban 2004: 250). Estas prácticas corporales y discursivas son capaces de elaborar el duelo, de ir integrando espacialmente el cuerpo individual y el social, de desatomizar. Se rescata lo negado (de fuera y de dentro) y se legitima: el discurso oficial deja paso al relato personal.

Un paso más en la resistencia al discurso hegemónico de la inseguridad que separa a los cuerpos es el hecho de "juntarse" para luchar por el espacio público. La destrucción de dos parques en 2005 por parte de la Administración consiguió reunir a sendos grupos de vecinos socialmente heterogéneos que organizaron manifestaciones, se apropiaron del espacio y tuvieron una experiencia de confluencia, de lucha y de relativo éxito (al ceder parcialmente el Ayuntamiento a la presión en una de las reivindicaciones). Resulta significativo que fuese la defensa de un espacio público, como un parque, la que movilizase sorpresivamente a cientos de vecinos. Además, las luchas por detentar poder de decisión en relación al futuro de los terrenos de la vieja cárcel de Carabanchel, así como las acciones contra los parquímetros $^{12}$, parecen haber reactivado en cierta medida la movilización social adormecida en las últimas dos décadas en el distrito. Al poner sobre la mesa el conflicto, al visibilizarlo, están forzando al barrio a posicionarse. Repolitizan la pertenencia empleando elementos de la historia pasada que se convierten en historia por hacer (Cassigoli 2006: 147) y de paso procuran ejemplos prácticos para todo el barrio de actuación performativa de la sociabilidad. Estas formas de practicar la ciudad constituyen un ejemplo de expansión de las ilegitimidades frente a la ciudad planificada por los poderes públicos.

Un último paso en estas resistencias actuadas con cuerpos que ahora se atreven a construir discursos (públicos), son las acciones de algunos pequeños colectivos del barrio frente a las redadas sistemáticas contra migrantes llevadas a cabo por la policía dentro de la lógica securitaria preventiva de la sociedad de control. Además, la organización de "pasacalles por un barrio mestizo" o la visibilización mediante cartografías y textos de los centros represivos del barrio, constituyen formas de construir discursos contrahege-

12 Mobiliario urbano dispuesto por el ayuntamiento para recaudar dinero por el aparcamiento de los coches en algunas calles del barrio. Este dispositivo ha sido objeto de manifestaciones, acciones ingeniosas y sabotajes por parte de muchos vecinos del barrio organizados en torno a algunos colectivos. El hecho de ser asimilado su barrio con otros de mayor poder adquisitivo a la hora de implantar el sistema de pago por aparcamiento, y no para recibir servicios deseados, ha sido el motor argumental de la movilización vecinal. 
mónicos. No arman un discurso de la seguridad frente al discurso de la inseguridad, sino que en cierto modo escapan de la lógica binaria para resignificar las lógicas de la sociedad de control y tratar de reintroducir la conciencia de clase en un barrio que ya no se considera obrero. Se debaten entre el fortalecimiento identitario del grupo y la apertura a la alteridad del barrio. Aún con poco éxito de convocatoria (quizás, en parte, por los restos identitarios que quedan), en estas luchas se recurre al discurso, a las tecnologías, pero sobre todo al cuerpo colectivo: la presencia simultánea de cuerpos y la apropiación del espacio que llevan a cabo siguen actuándose como formas de practicar el empoderamiento, y todo ello a pesar del miedo a determinadas agresiones. No es su discurso el que convence al resto de vecinos del barrio, sino que su potencia política se encuentra en la actuación performativa de los vínculos barriales.

\section{CONCLUSIONES}

En el presente artículo he tratado de efectuar un recorrido que va desde la materialización de las políticas de control y de las lógicas higienistas y estéticas de la sociedad de consumo sobre las calles y los cuerpos en Carabanchel, hasta las formas de apropiación y de resignificación que efectúan los vecinos y vecinas de dicho distrito. Partiendo del marco teórico decerteano, he dividido estas formas de apropiación y resignificación en discursivas, orales y corporales, considerando las primeras como más cercanas al mundo de la identidad y de las estrategias, y las segundas y las terceras (oralidad y corporalidad) como concernientes a la alteridad y a las tácticas. Parto, por lo tanto, de la existencia de estilos diferentes en la forma de practicar la inseguridad y el miedo en el barrio: unos que persiguen su refugio en lugares (la sobrelocalización ${ }^{13}$ en forma de discursos fuertemente identitarios, patrias, urbanizaciones cerradas...), otros que tienden a permanecer más en los no lugares para gestionar los conflictos (sin negarlos) y que se comunican desde el polo femenino de lo corp-oral y, por último, otros que participan de ambas categorías en su vida cotidiana y en los ámbitos públicos que construyen, y al mismo tiempo intentan romper esta dicotomía entre lugares y no lugares, entre público y privado, entre masculino y femenino, entre nacionales y extranjeros, con el fin de encontrar en la diversidad lo que hay de común en Carabanchel. Su afirmación se realiza con un discurso, o un contradiscurso, pero éste viene desde abajo, se construye más horizontalmente y se actúa performativamente juntan-

\footnotetext{
${ }^{13}$ Marc Augé se refiere al retorno al "lugar" de quien frecuenta los "no lugares" en esta sobremodernidad (Augé 2004: 110).
} 
do sus cuerpos en el espacio público. Más allá de sus contenidos discursivos, podemos ver en ellos la sociabilidad en acción que enlaza con ese común. Un común que combate el aislamiento sin negar el miedo e intentando no reproducir la cadena del sacrificio de la violencia. Desde la identidad, desde la soledad del discurso, desde lo más masculino, se trazan estrategias y parece haber miedo al miedo; desde la alteridad que aflora en la corporalidad, sin embargo, se legitima el miedo en el encuentro desde las propias vulnerabilidades y se actúan las tácticas: sin miedo al miedo.

\section{BIBLIOGRAFÍA CITADA}

Amuchástegui, A. 2007. "La verdad... yo no creía que era violento", en R. Parrini (coord.), Los contornos del alma, los limites del cuerpo: género, corporalidad y subjetivación: 155-181. México: PUEG-UNAM.

Augé, M. 2004. Los no lugares. Espacios del anonimato. Barcelona: Gedisa.

Bauman, Z. 2006. La globalización. Consecuencias humanas. México: FCE.

Blair, E. 2005. Muertes violentas. La teatralización del exceso. Medellín: INER-Universidad de Antioquia.

Bourdieu, P. 2008. El sentido práctico. Buenos Aires: Siglo XXI.

Butler, J. 2007a. "¿Qué es la crítica?”, en R. Parrini (coord.), Los contornos del alma, los límites del cuerpo: género, corporalidad y subjetivación: 35-58. México: PUEG-UNAM.

Butler, J. 2007b. El género en disputa. Barcelona: Paidós.

Caldeira, T. 2000. City of walls. Crime, Segregation and Citizenship in Sao Paulo. Berkeley: University of California Press.

Cassigoli, R. 2006. "Usos de la memoria: prácticas culturales y patrimonios mudos". Cuicuilco 38: 133-151.

Cassigoli, R. 2007. "Memoria y relato en la obra de Michel de Certeau", en M. Aguiluz y G. Waldman (coords.), Memorias incógnitas. Contiendas en la historia. México: UNAM.

Davis, M. 1992. City of Quartz. Excavating the future in Los Angeles. Nueva York: Vintage.

De Certeau, M. 1993. La escritura de la historia. México: UIA.

De Certeau, M. 1996. La invención de lo cotidiano. I Artes de hacer. México: UIA-ITESOCFEMC.

De Certeau, M. 1997. "Historias de cuerpos". Historia y grafía 15: 36-45.

De Certeau, M. 2006. La escritura de la historia. México: UIA-ITESO.

De Giorgi, A. 2006. El gobierno de la excedencia. Postfordismo y control de la multitud. Madrid: Traficantes de sueños.

Delgado, M. 2007a. Sociedades movedizas. Pasos hacia una antropología de las calles. Barcelona: Anagrama.

Delgado, M. 2007b. "Entrevista a Manuel Delgado. La verdad está ahí fuera". Cultura Urbana 4. http://www.cultura-urbana.cl/entrevistamanueldelgado.pdf (10-08-2007).

Esteban, M. L. 2004. Antropología del cuerpo. Género, itinerarios corporales, identidad y cambio. Barcelona: Bellaterra.

García García, S. 2008. "Inseguridad, poder y biografía en un contexto barrial: el caso de Carabanchel". Gazeta de Antropología 24. http://www.ugr.es/ pwlac/G24_18Sergio_ Garcia_Garcia.html (15-06-2008).

Hardt, M. y Negri. A. 2005. Imperio. Barcelona: Paidós. 
Low, S. 2004. Behind the Gates: Life, Security, and the Pursuit of Happiness in Fortress America. Nueva York: Routledge.

Naranjo, G.; Hurtado, D. y Peralta Agudelo, J. 2001. Ciudad y ciudadanía. Bajo la lente del conflicto urbano. Medellín: Corporación Región.

Ramos, J. 1996. Paradojas de la letra. Caracas: Escultura-CONAC/Venezuela-Universidad Andina Simón Bolívar (Subsede Ecuador).

Reguillo, R. 2002. "Violencias y después culturas en reconfiguración", en Lanic Extext Collection, http://lanic.utexas.edu/project/etext/llilas/cpa/spring03/culturaypaz/ reguillo.pdf (11-6-2009).

Reguillo, R. 2005. "Ciudad, riesgos y malestares. Hacia una antropología del acontecimiento", en N. García Canclini (coord.), La antropología urbana en México: 307-340. México: CNCA, UAM, FCE.

Scheper-Hughes, N. 1997. La muerte sin llanto. Violencia y vida cotidiana en Brasil. Barcelona: Ariel.

Serret, E. 2004 "Mujeres y hombres en el imaginario social. La impronta del género en las identidades", en I. García Gossio (coord.), Mujeres y sociedad en el México contemporáneo. Nombrar lo innombrable. México: TEC de Monterrey-Cámara de Diputados-Miguel Ángel Porrúa.

Taussig, M. 1995. Un gigante en convulsiones. El mundo humano como sistema nervioso en emergencia permanente. Barcelona: Gedisa.

Wacquant, L. 2001. Parias urbanos. Marginalidad en la ciudad a comienzos del milenio. Buenos Aires: Manantial.

Fecha de recepción: 5 de febrero de 2009

Fecha de aceptación: 16 de junio de 2009 